\title{
Synergic effect of recycled cotton fabric and wood saw dust reinforced biodegradable polypropylene composites
}

\author{
M. K. Islam ${ }^{1 *}$, A. Sharif ${ }^{1}$, M. Hussain ${ }^{2}$ and I. Hassan ${ }^{2}$ \\ ${ }^{I}$ Department of Materials and Metallurgical Engineering, Bangladesh University of Engineering and Technology (BUET), \\ Dhaka-1000, Bangladesh \\ ${ }^{2}$ Dept. of Chemical Engineering, Hanyang university Erica Campas, Sannok-Gu, Gyeongi-do 426-791, Korea
}

Received: 22 March 2018

Revised: 16 April 2018

Accepted: 23 May 2018

DOI: https://doi.org/10.3329/bjsir.v54i1.40727

\begin{abstract}
Hybrid polymer matrix composites of waste cotton fabric and wood saw dust reinforcements were studied with a view to recycling the wastes from garments and carpentry industries. Polymer composites with cotton fabric and wood-saw-dust reinforcements were fabricated using hot press machine. Their physical, thermal and mechanical behaviors were discussed in terms of moisture absorption, thermal stability, tensile strength, elastic modulus, flexural strength and flexural modulus. Compositional analyses of fibers, matrix and composites were carried out with FTIR spectroscopy. Experimental results revealed that tensile and flexural strength of the composites increased with cotton fabric reinforcement. On the other hand, with increasing wood saw dust strength decreased up to a certain limit and then increased again. Water absorption of the hybrid composites increased substantially with increasing natural filler contents. Maximum water absorption was observed in $20 \%$ fabric/wood-saw-dust reinforced polymer composite. Furthermore, TGA graphs suggest better thermal stability of the hybrid composites than that of pure polypropylene.
\end{abstract}

Keywords: Recycling; Hybrid; Cotton fabric; Wood saw dust; Polypropylene, Composite.

\section{Introduction}

In recent decades, natural fibers as an alternative reinforcement in polymer composites have been the subject of interesting research due to their advantages over conventional glass and carbon fibers (Lee et al., 2009). While, natural fibers traditionally have been used to fill and reinforce thermosets, natural fiber reinforced thermoplastics especially polypropylene composites, have attracted much attention due to their added advantage in recyclability (Nam and Netravali, 2006). Natural fiber composites are also claimed to offer environmental advantages such as reduced dependence on non-renewable energy/material sources, lower pollutant emissions, lower greenhouse gas emissions, enhanced energy recovery, and end of life biodegradability of components. Also, they are readily available and their specific properties are comparable to those of other fibers used for reinforcements. However, the certain drawbacks of natural fibers/polymers composites are the incompatibility between the hydrophilic natural fibers and the hydrophobic thermoplastic matrices. This leads to undesirable properties of the composites. It is therefore necessary to modify the fiber surface by employing chemical modifications to improve the adhesion between fiber and matrix (Esfandiari, 2008). The biodegradability, low density, a range of mechanical properties, less abrasiveness compared to synthetic fibers make lignocellulosic fibers attractive to be used as reinforcement in polymer matrix composites (Islam and Sharif, 2016; Shubhra et al., 2010; Seki et al., 2010; Biswas et al., 2011). Cotton is one of the most recognized lignocellulosic fibers used in several applications varying from common fabrics to composites (Eleiche and Amin, 1986; Alsina et al., 2005; Fervel et al., 2003; Tserki et al., 2003). Cotton waste has been used as reinforcing fibers for the preparation of cost-effective and biodegradable composites and was reported to enhance significantly the biodegradation rate.

\footnotetext{
*Corresponding author e-mail: mme012@yahoo.com
} 
A large amount of garments waste is being generated every day from garment industries from the abscission of the fabrics. In addition, a substantial amount of waste comes as post-consumer waste which is the product that the owner no longer needs it and hence decides to discard (Wang, 2010; Tanvir and Mahmood, 2014 ). These products are discarded as they are damaged, discolored, torn out or have become out of fashion. The waste materials need a large space for dumping. These industrial wastes might be a great threat to the environment if they are left unused. From the environmental point of view it is essential to manage the wastes by reusing or recycling (Aspiras and Manalo, 1995).

Another notable waste material is wood saw dust which is produced as a by-product in saw mills and carpentry works form cutting, grinding and polishing of woods. Wood saw dust is a natural fiber which has tendency to absorb water. As a consequence wood saw dust considerably improves biodegradability of polymer matrix composites while used as reinforcement of polymer (Adhikary et al., 2008; Hossain et al., 2014; Pérez et al., 2012). The manufacture of environment friendly biodegradable polymer matrix composites has a great importance for the sake of green environment. Biodegradable polymer matrix composites have a very wide range of applications including agriculture, packaging, transportation, medicine, electrical/electronic appliances, and home appliances.

The aim of this study is to develop an environment friendly biodegradable hybrid polymer matrix composite with waste cotton fabric and wood saw dust reinforcement that will be cost effective as well. For this purpose locally produced wood saw dust and waste cotton fabric were utilized as reinforcement in manufacturing hybrid polypropylene composites. In this study, attempt was made to investigate the mechanical, thermal and physical properties of cotton fabric and wood saw dust reinforced hybrid polypropylene composites for potential applications.

\section{Material and method}

Waste cotton fabric was collected from a local garments industry. Maximum strength and modulus of the waste cotton fabric was 34.1 $\mathrm{MPa}$ and 283.8 $\mathrm{MPa}$. The mechanical and thermal properties of cotton fabric fiber, used in this study, have been shown in Table I.

Table I. Mechanical and Thermal properties of cotton fabric

\begin{tabular}{ll} 
Maximum Strength & $34.12 \mathrm{MPa}$ \\
Elastic Modulus & $283.3 \mathrm{MPa}$ \\
Onset Temperature (TGA) & $265^{\circ} \mathrm{C}$ \\
\hline
\end{tabular}

Table II. List of nomenclature used in this study

\begin{tabular}{ll}
\hline Abbreviation & Full Name \\
PP & Polypropylene \\
PF & Fabric reinforced polymer composite \\
PF10W & Fabric/10\% wood particle reinforced polymer \\
& composite \\
PF15W & Fabric/15\% wood particle reinforced polymer \\
& composite \\
PF20W & Fabric/20\%wood particle reinforced polymer \\
& composite \\
\hline
\end{tabular}

Wood saw dust (Kerosene- Copaifera langsdorffii) particle, which is a carpentry waste, was collected from the carpentry shop of Bangladesh University of Engineering and Technology (BUET). Commercially available polypropylene granules were purchased from local market. True density of kerosene wood saw dust was $112 \mathrm{~kg} / \mathrm{m}^{3}$. Waste cotton fabric was washed properly with detergents to remove dirt and to improve adhesion with the matrix material. Then the fabric was dried in the sun naturally. Fabric was cut as per the dimension of the mold. By sieve analysis, wood saw dusts of below 210 micron size were separated to use as reinforcement of composites. Wood saw dust was dried in oven at $70-80^{\circ} \mathrm{C}$ for several hours to remove moisture. Finally, the dried wood saw dust was packed into air tight polyethylene bag and preserved in an air tight box to prevent further moisture absorption.

In this study, the composites were developed in Fontune Hot Press Machine. An aluminium die measuring $150 \mathrm{~mm} \times 150 \mathrm{~mm}$ was used. The die was cleaned thoroughly before composite manufacturing. For each composite sample, $80 \mathrm{~g}$ polypropylene granules were used. Required amount of wood saw dust particles were measured for 10, 15 and 20 wt. \% reinforcement. In all the cases, a layer of cotton fabric was used over the whole cross section, i.e., amount of cotton fabric was constant for all the composites. Among them one composite was developed using only fabric as reinforcement. A schematic drawing of the composite developed is shown in Fig. 1.

For developing composites, first the die was cleaned carefully, and then sprayed with silicone as a mold release as to avoid sticking of the composites to the mold surface. Both dried wood saw dust and commercial polypropylene were taken into a beaker with a view to mixing fiber and polymer 


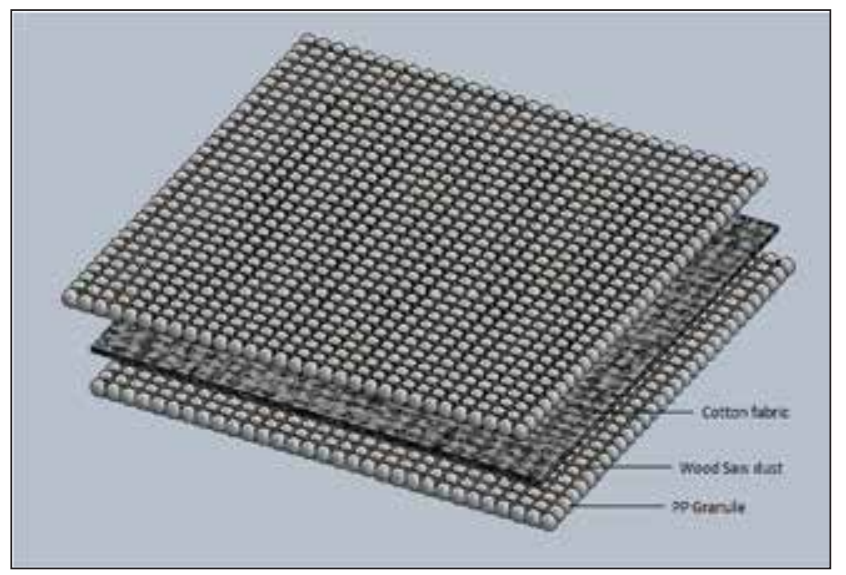

Fig. 1. Schematic drawing of composite preparation

matrix uniformly. Single cotton fabric fiber was sandwiched between layers of polypropylene and wood saw dust particles. Then, the uniform mixture of fiber and polypropylene was taken into the aluminum die and placed into the hot press machine chamber. For developing the hybrid composites, a $30 \mathrm{kN}$ load was applied in hot press machine. Heating and cooling cycle involves heating at 160 ${ }^{\circ} \mathrm{C}$ for 10 minutes. Thereafter, the temperature was increased to $180{ }^{\circ} \mathrm{C}$. After that the die along with hot pressed composites was cooled to room temperature by passing cold water over the plates of the hot press machine. After cooling, the developed composite was taken out from the die.

Tensile test of the composites was carried out in Instron Universal Testing Machine (Model 5969) according to the ASTM D 638-02a standard at a crosshead speed of $2 \mathrm{~mm} / \mathrm{min}$. Flexural tests were also carried out in Instron Universal Testing Machine according to ASTM D 790-00 at a crosshead speed of $2 \mathrm{~mm} / \mathrm{min}$. The dimension of the specimen used was $75 \mathrm{~mm} \times 12.5 \mathrm{~mm} \times 3.5 \mathrm{~mm}$. The flexural strength and modulus were calculated using the following equations.

$$
\begin{aligned}
& \text { Flexural strength, } \mathrm{Pa} \sigma_{f}=\frac{3 P L}{2 b d^{2}} \\
& \text { Flexural modulus, } \mathrm{Pa} \mathrm{E}=\frac{L^{3} m}{4 b d^{2}}
\end{aligned}
$$

Where, $\mathrm{P}$ is the maximum applied load in Newton $(\mathrm{N}), \mathrm{L}$ is the length of support span in meter $(\mathrm{m}), \mathrm{m}$ is the slope of the tangent $(\mathrm{N} / \mathrm{m}), \mathrm{b}$ and $\mathrm{d}$ are the width and thickness of the specimen respectively in meter $(\mathrm{m})$.

Hardness test of the specimen was carried out in Shore A scale by Bareiss HPE II Hardness Tester. Ten readings were taken for every specimen and the average result was shown as the hardness of the specimen. Since the bio-filler reinforced composites absorb moisture, the mechanical property of composites must degrade. Thus, water absorption test of the developed composites was carried out at boiling water $\left(100^{\circ} \mathrm{C}\right)$ according to the standard ASTM D 570-98. The sample dimension was $75 \mathrm{~mm} \times 25.4 \mathrm{~mm} \times 3.5 \mathrm{~mm}$. Before immersion in boiling water, conditioning/drying of the specimen was performed at an oven at $105-110^{\circ} \mathrm{C}$ for 1 hour period. Then they were cooled in a desiccator and weighed in a balance. The specimens were immersed in boiling distilled water. After 2 hours immersion, they were removed and cooled in distilled water. After 15 minutes they were removed and reweighed in the same balance. The percentage of water absorption was calculated using the equation

$$
\mathrm{A}, \%=\frac{M w-M c}{M c} \times 100 \%
$$

Where, $\mathrm{Mw}=$ Mass of the specimen in wet condition

$\mathrm{Mc}=$ Mass of the specimen in conditioned/dried state

After tensile tests, fracture surfaces were cut for fractographic analysis. Fractographic observation of the fracture surfaces of composites was performed in SEM JEOL JSM-7600F (USA). During fractographic analysis, $3 \mathrm{KV}$ accelerating voltage was used. Under SEM, various fracture features were observed and they were photographed in different magnification. The fractographic investigation was performed at the Department of Glass and Ceramic Engineering in Bangladesh University of Engineering and Technology (BUET). Fourier Transformed Infrared (FTIR) spectroscopic analysis of the fibers, polypropylene matrix and composites was carried out in FTIR spectrometer (Model: Nicolet 380, USA) which uses KBr pellet technique. Polypropylene, fibers and composites were ground and mixed with $\mathrm{KBr}$ at a ratio of $\mathrm{KBr}$ : sample $=100: 1$ and then pressed to make a pellet for FTIR measurement. The range of wave number was between $400 \mathrm{~cm}^{-1}$ and $4000 \mathrm{~cm}^{-1}$. For thermal stability analysis, the decomposition rates were measured by a SETARAM TGT DTA 92 thermo-gravimetric apparatus. At first, the sample to be analyzed was introduced into a platinum crucible. The mass variation of the sample (TG) was then measured as a function of temperature, and the rates of mass loss (DTG) were determined by using a thermo-balance under an inert gas nitrogen atmosphere up to $600{ }^{\circ} \mathrm{C}$, at a heating rate of $10^{\circ} \mathrm{C} \mathrm{min}^{-1}$.

\section{Results and discussion}

Fig. $2(a, b)$ shows the tensile strength and Young's modulus of the hybrid composites. From the bar chart it is clear that tensile strength of only cotton fabric reinforced polymer matrix composite was higher than that of commercially pure polypropylene (PP). This was due to the stress transfer of the 


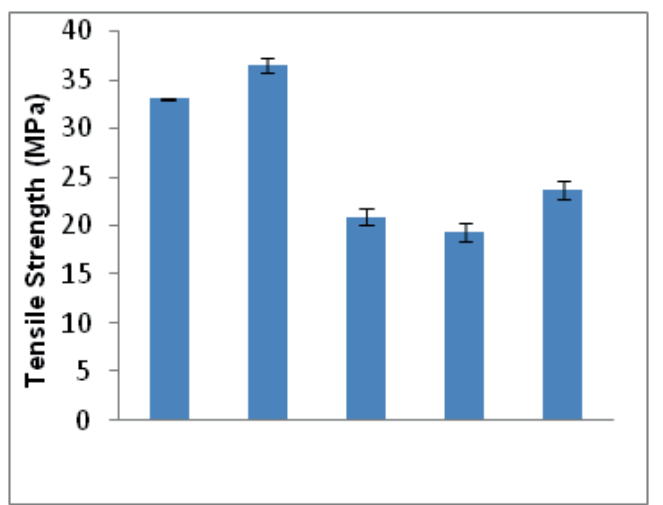

(a)

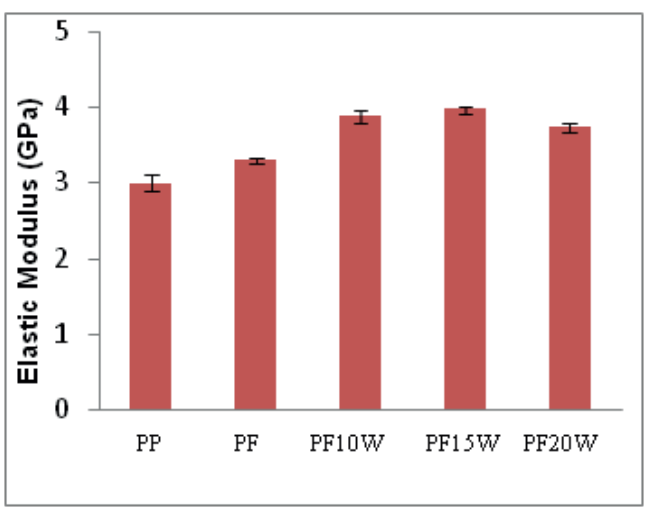

(b)

Fig. 2. (a) Tensile strength and (b) elastic modulus of PP and hybrid composites

matrix to the fabric fibers. However, it was noted that the strength of wood saw dust reinforced polymer matrix composites decreased with increasing filler content. In general, fiber-reinforced composites have higher tensile strength than particle reinforced composites (Liu, 1997). Tensile strength of untreated waste cotton fabric reinforced PP composite is found as $36.5 \pm 0.8 \mathrm{MPa}$ in this study. In a similar study, strength of untreated jute fiber mat reinforced polypropylene composites

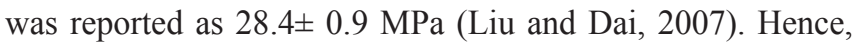
superior tensile strength of cotton fabric reinforced polypropylene composite can be obtained compared to jute fiber mat reinforced polypropylene composites. It is noteworthy that, this superior strength has been possible to achieve using waste cotton fabric encompassing very low mechanical properties. However, with the increase in the proportion of wood particles, their uniform mixing and distribution inside the matrix became difficult and agglomeration (clusters)of wood particles were formed at various locations in the composites. As cluster of wood particle has no or little interface bonding strength within itself, it behaved as a weak point in the structure and cracks were formed easily during tensile test. Thus the composite strength gradually decreased with increase in the proportions of the wood particles. Size of wood particle has also significant effect on the tensile strength of the composites. It was already shown that the increase in the proportion and size of wood particles decreased the composite strength (Stark and Rowlands, 2003). Further work is under investigation to improve the filler-polymer interfacial bonding by coating saw dust with suitable coupling agents.

Interestingly, in case of $20 \%$ reinforcement strength of hybrid composites increased slightly in this study. As shown in Fig. 2 (b), the increase in elastic modulus with increasing filler content was also in agreement with other researchers (Tserki et al., 2003). It is expected that the incorporation of sawdust into the soft thermoplastic increased the rigidity of the composites. A slight decrease in the elastic modulus was observed in case of $20 \%$ reinforced composites.

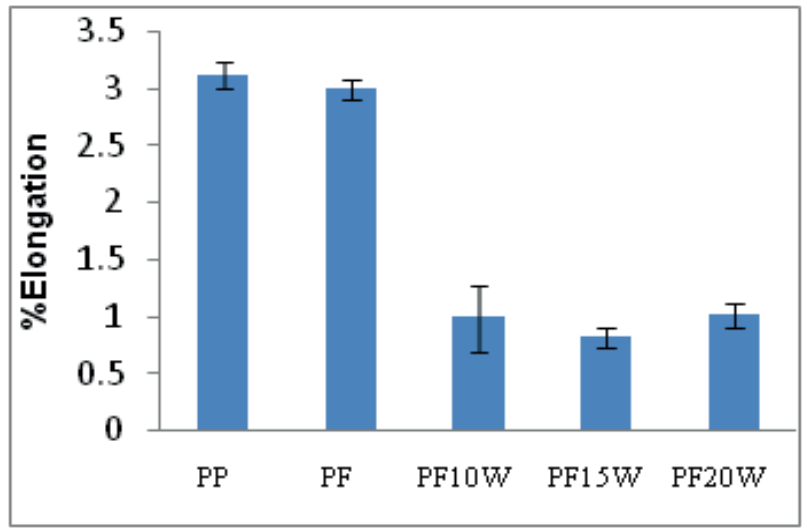

Fig. 3. Percent elongation of PP and hybrid composites

Maximum percentage elongation of PP and hybrid composites before fracture is shown in Fig. 3. Elongation of the composite reinforced with only fabric decreased slightly from the virgin PP. It was observed that, elongation of the hybrid composites drastically falls with increasing percentage of wood saw dust. This result suggests lower ductility of the hybrid composites than that of virgin polypropylene. Similar result was also reported by others (Ichazo et al., 2001).

Fig 4(a, b) shows the flexural strength and flexural modulus of the hybrid composites. Experimental data illustrate that flexural strength of fabric reinforced polymer matrix composite increased substantially whereas, flexural strength decreased gradually with increasing percentage of wood saw dust particles while reinforcement of fabric kept constant. This may be attributed to the poor interaction between hydrophobic matrix and hydrophilic reinforcement. Khalil et al. (2007) stated poor interfacial bonding between fiber and 


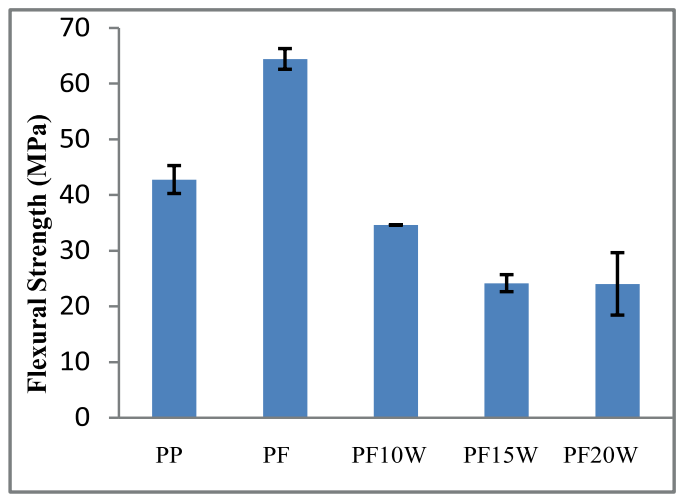

(a)

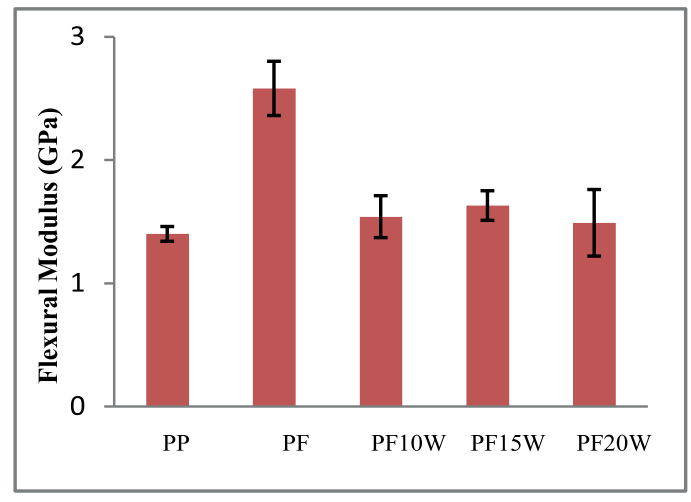

(a)

Fig. 4. (a) Flexural strength and (b) Flexural modulus of PP and hybrid composites

matrix leads to poor flexural properties.It is found that cotton fabric fiber substantially improved flexural properties compared to wood saw dust particles reinforcement, similar results were reported in case of woven mat fiber and chopped fiber (Jawaid et al., 2011a). Additionally, the woven cotton fabric consists of long continuous fibers having enhanced load bearing properties compared to short discontinuous wood saw dust fibers in the matrix. The flexural strength values are dependent very much on the fiber orientation and the location of resin-rich area (Sastra et al., 2005). In this study, flexural strength of untreated cotton fabric reinforced polypropylene composite was $64.4 \pm 1.8 \mathrm{MPa}$ whereas, flexural strength of untreated jute fiber mat reinforced polypropylene composites was reported as $35.1 \pm 1.2 \mathrm{MPa}$ (Liu and Dai, 2007). It is indicative that much higher flexural strength can be attained in waste cotton fabric reinforced PP composites compared to jute fiber mat reinforced PP composites.

The flexural modulus is a measure of resistance to deformation of the composite in bending. The flexural modulus of cotton fabric reinforced composite was higher compared to the wood saw dust particles based hybrid composites. It can be due to weave architecture and long continuous fibers, which make their flexural properties better compared to short discontinuous fibers in the wood saw dust and fabric reinforced composites (Jawaid et al., 2011b).

With increasing wood saw dust filler contents, flexural modulus also increased up to $15 \%$ reinforcements and decreased while reinforcements came to $20 \%$. However, variation in flexural modulus due to variation in only wood saw dust content is slight compared to cotton fabric reinforcement. An optimum composition of reinforcements in the hybrid composites would be found to optimize strength and modulus of the composites by further investigation with varying compositions (Zainudin et al., 2014).

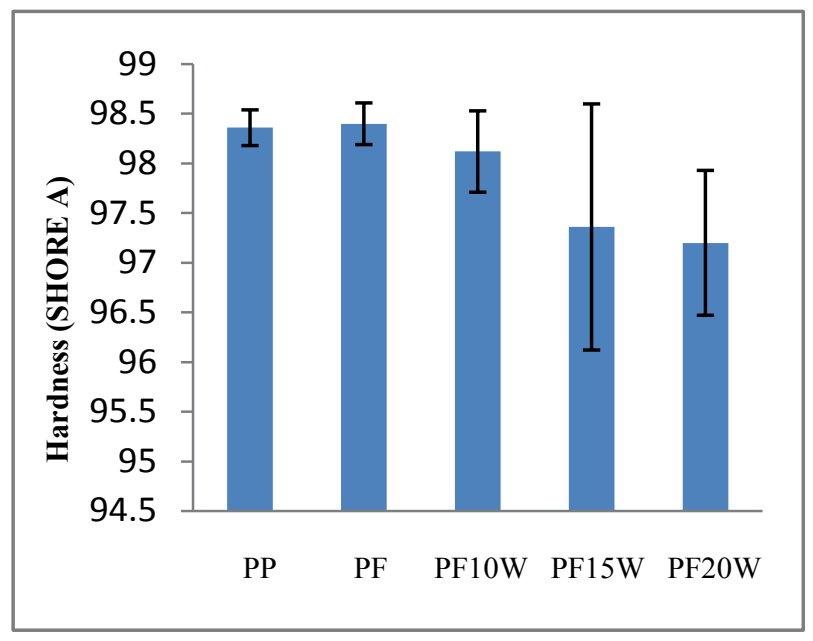

Fig. 5. Hardness of PP and hybrid composites

Hardness results of the pure PP and hybrid composites are compared in Fig 5. The change in hardness of the composites, due to incorporation of wood saw dust particles into the polymer matrix, was insignificant . Experimental results showed that pure PP and cotton fabric reinforced PP composite had maximum hardness. Hardness of $20 \%$ short jute fiber reinforced PP composite was reported as $96 \pm 0.5$ Shore-A (Khan et al., 2012). In this study, hardness of $P P$ and cotton fabric reinforced PP was $98.2 \pm 0.2$ Shore-A whereas, in case of $20 \%$ wood saw dust and cotton fabric reinforced composite it was $97 \pm 0.6$ Shore-A slightly higher than that of the reported data. With increasing percentage of wood saw dust, hardness value of the composites decreased slightly. This phenomenon ensures the presence of wood saw dust fillers inside the composites not just at the outer surface. Another thing to be noted is that, the scattering of data increased with increasing wood particle content. This might be due to the increasing probability of indenting the tester on wood particles clusters which were loosely bonded and hence less resistant to indentation. 
Water absorption of PP and hybrid composites is shown in Fig. 6. The results obtained revealed minimum water absorption in pure PP whereas, it was maximum with the $20 \%$ wood saw dust/fabric reinforced composite. This is almost 4.50 times more than that of the virgin PP. It is noted that water absorption increased with increasing wood particles content in the composites. Generally, all natural fibers have a tendency to absorb water and possess low wettability by hydrophobic resins due to presence of hydrophilic hydroxyl groups of cellulose, hemicellulose and lignin in the fibers.

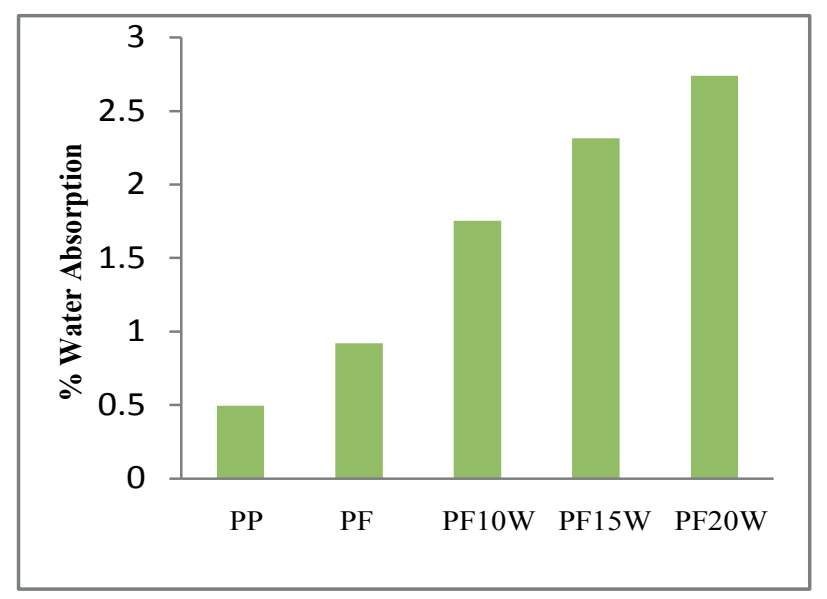

Fig. 6. Percentage of water absorption of PP and hybrid composites

Hemicellulose is mainly responsible for the biodegradation, moisture absorption, and thermal degradation of the fiber as it shows least resistance and thus leads to the bio degradation of composites (Saheb and Jog, 1999). However, non-crystalline cellulose and lignin also play an important role in water uptake process. Water diffusion in polymeric composites is governed by the three mechanisms. The first involves diffusion of water molecules inside the micro gaps between polymer chains. The second involves capillary transport into gaps and finally flaws at the interfaces between fiber and matrix. Another cause is transport by micro cracks in the matrix (Thwe and Liao, 2002). Absorption of water in composites causes swelling of fiber till the cell walls are saturated with water and beyond that water exists as free water in the void structure subsequently leading to composites delamination or void formation. Absorbed water weakens interfacial adhesion and causes hydrolytic degradation of both matrix and fiber (Gibson et al., 2002). Cracking and blistering of fiber cause high water absorption, while degradation causes leaching of small molecules (Bao and Yee., 2002). With increase in wood particle content and time period, the total water intake also increased (Bismarck et al., 2002). Thus, the overall water absorption of the composites increased with wood particle content.
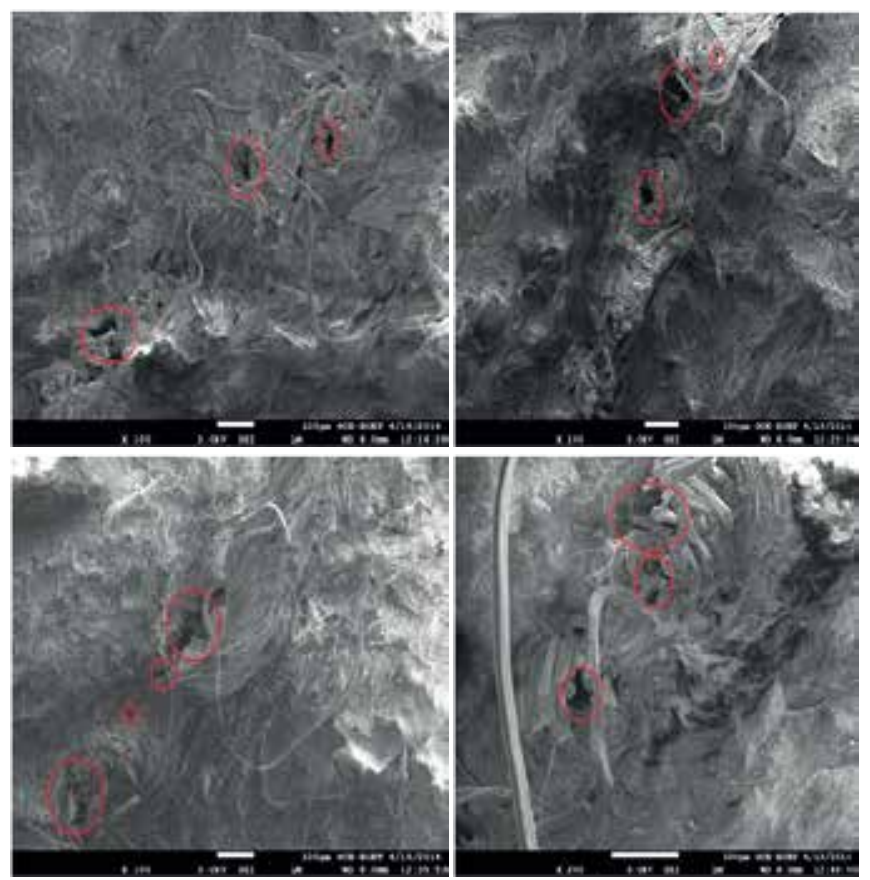

Fig. 7. Scanning electron micrograph of (a) fabric reinforced and (b) fabric-10\% wood saw dust (c) fabric- $15 \%$ wood saw dust (d) fabric-20\% wood saw dust reinforced composite.

Fig. 7 (a-d) shows scanning electron micrographs (SEM) of the tensile fracture surfaces of the composites. From SEM images distinct clusters and micro pores were observed at the interfaces of fabric, polypropylene matrix and wood saw dust particles. The pores are clearly visible in the micrographs encircled by red circles. This type of mismatch between matrix and fibers occurs due to the hydrophilic and hydrophobic characteristics of natural fibers and polypropylene matrix respectively. These micro pores always act as stress concentrators in polymeric composites when they are loaded in tensile test. Due to the poor interfacial bonding between filler and matrix polymer, the pull-out of fillers can be seen in the SEM micrographs. However, the fracture surface of the virgin polypropylene indicates ductile failure while the tensile fracture behavior in all the composites was found to be almost brittle type. It is believed that poor bonding between fillers and matrix leads to the brittle fracture of the composites (Yang et al., 2004).

With increase in wood particle, tendency of cluster formation became very severe. This type of cluster formation has been thought to be responsible to reduce the strength of the wood 
particle reinforced composites with increase in the proportion of wood particle. It was reported that interface bonding and adhesion between matrix and fiber can be improved by chemical treatment of the fibers (Snijder and Bos, 2000). It was already established that surface morphology of treated saw dust PP composites differ in smoothness and roughness than the raw sawdust-PP composites (Idrus et al., 2011).

FTIR spectrum of polypropylene, wood saw dust, cotton fabric and composite (PF15R) is shown in Fig. 8 and Fig. 9. In these figures, there are some spectra which can be assigned to some specific components, where the relative intensities of the peaks correspond to the relative amount of that component in the fiber. However, in the present study only qualitative analysis was performed rather than quantitative.

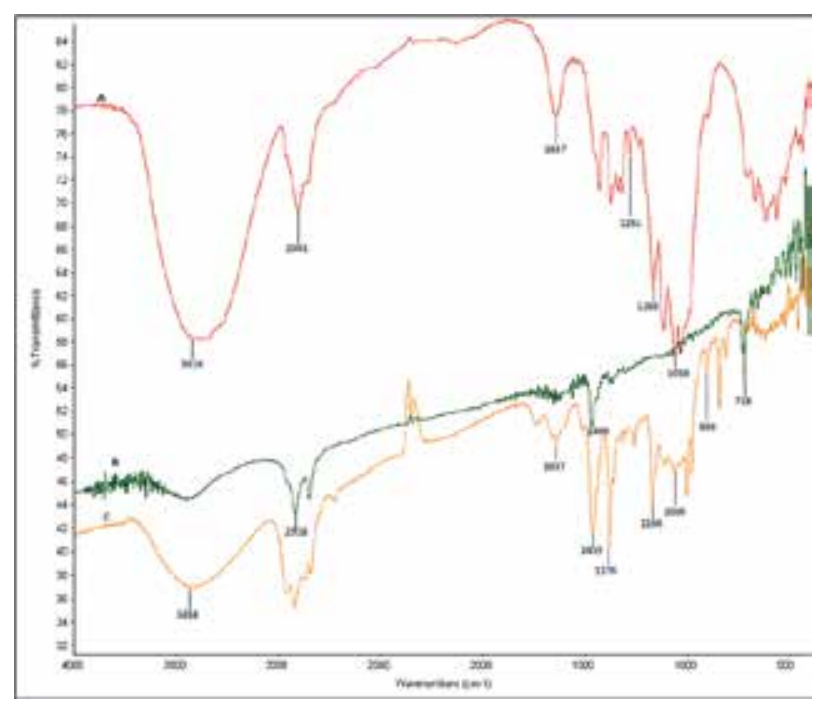

Fig. 8. FTIR spectrum of (A) Cotton fabric (B) Polypropylene (C) PF15W composite

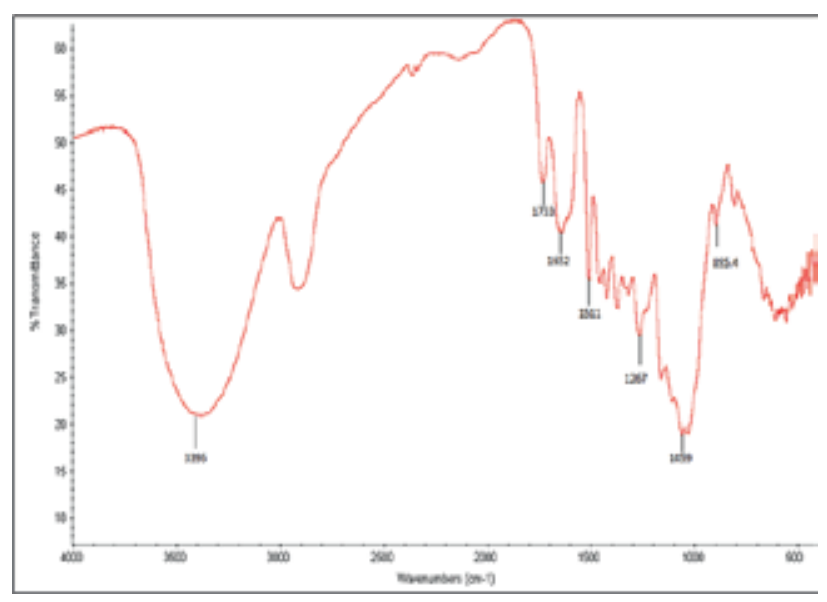

Fig. 9. FTIR spectrum of wood saw dust particles
The $\mathrm{C}=\mathrm{C}$ in plane aromatic vibration at $\sim 1511 \mathrm{~cm}^{-1}$ from lignin, $\mathrm{C}=\mathrm{O}$ ester band at $\sim 1732 \mathrm{~cm}^{-1}$ from pectin, $\mathrm{O}-\mathrm{H}$ bending of absorbed water at $\sim 1637 \mathrm{~cm}^{-1}$, peak around 3400 $\mathrm{cm}^{-1}$ is the characteristic of $\mathrm{O}-\mathrm{H}$ stretching mode of alcohol, at $\sim 1163 \mathrm{~cm}^{-1} \mathrm{C}-\mathrm{C}$ ring breathing band attributed to polysaccharide components of natural fibers, mostly cellulose (Garside and Wyeth, 2003). The transmittance peaks in 1459 $\mathrm{cm}^{-1}$ and $1376 \mathrm{~cm}^{-1}$ indicate asymmetric in plane $\mathrm{CH}_{3}$ bending and symmetric $\mathrm{C}-\mathrm{H}$ bending respectively, microstructure of both of which is amorphous (Parthasarthy et al., 2002). The $1459 \mathrm{~cm}^{-1}$ peak is present both in virgin PP and composites, where $1376 \mathrm{~cm}^{-1}$ peak appeared in composites. The microstructure of the components showing these peaks are amorphous, which may be attributed to the brittle type failure of composites containing wood saw dust particles. The reduced mechanical properties of wood saw dust reinforced composites compared to pure PP and PP/cotton fabric composite may also be attributed to the appearance of new amorphous phase in the composites.

Presence of water absorption peak around $1637 \mathrm{~cm}^{-1}$ in wood saw dust, cotton fabric and composites signifies that fibers as well as composites were not completely free from moisture. From comparative study of the combined figure of PP, fabric, composites and wood saw dust, it is observed that the characteristic peaks of both fibers and polymer matrix is present in the composites, although their relative intensities varies due to the differential domination of the constituents of matrix and fibers. Hence, it can be concluded that, there has been very negligible chemical reactions between the matrix and fibers to bring any significant change in their structures and properties. Polypropylene matrix and fibers retained their individual characteristics and co-existed in the composites.

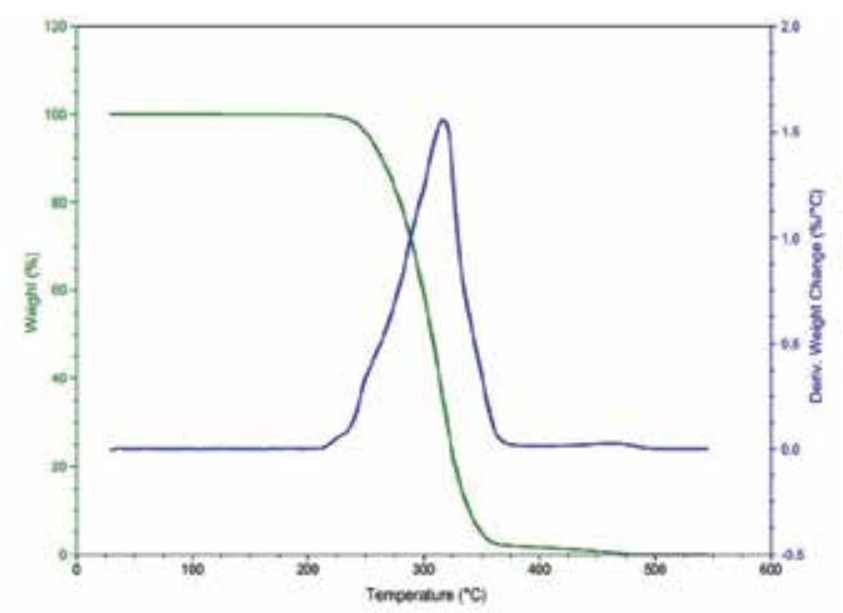

Fig. 10. Weight vs. Temperature graph for polypropylene 
Thermal stability of pure polypropylene matrix is shown in Fig. 10. A TGA curve of fabric- $15 \%$ wood saw dust reinforced hybrid composite is shown in Fig. 11, which is the representative of all three composites, since there found very negligible variations in the thermal stability of composites with varying filler contents.

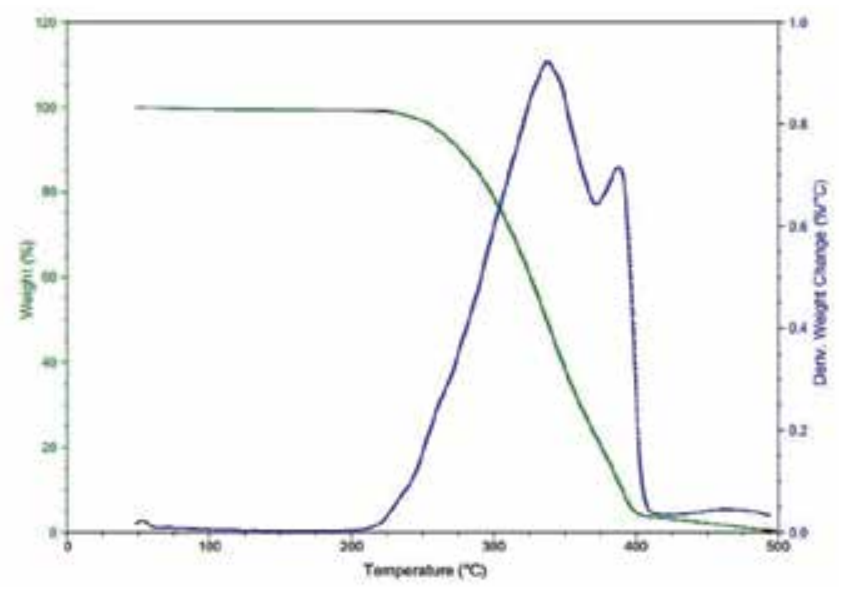

Fig. 11. Weight vs. Temperature graph for fabric-15\% wood saw dust reinforced hybrid composite

Table III. Thermo-gravimetric analysis of composites

\begin{tabular}{lllll}
\hline Properties & Pure PP & PF10W & PF15W & PF20W \\
Onset temperature $\left({ }^{\circ} \mathrm{C}\right)$ & 267 & 279 & 279 & 271 \\
Degradation temperature $1\left({ }^{\circ} \mathrm{C}\right)$ & 317 & 334 & 337 & 341 \\
Degradation temperature 2 $\left({ }^{\circ} \mathrm{C}\right)$ & N/A & 387 & 387 & 379 \\
\hline
\end{tabular}

Table III shows the thermal degradation behavior of the hybrid composites. TGA data indicate that the composites had negligible amount of moisture ensuring that wood saw dusts contained very low moisture. Virgin PP in TGA shows only one peak whereas composites show two peaks (i.e. one is for the constituents of PP and another for reinforcing materials). Similar results were reported by other researchers in case of recycled HDPE/natural fiber composites (Lei et al., 2007). From Table III it is observed that, with incorporation of fillers, the onset temperature as well as degradation temperature increases indicating a better thermal stability. Although the difference in onset and degradation temperature between virgin polypropylene and reinforced composites was significant, with increasing filler contents there found a very negligible change in the aforementioned temperatures of the composites. Results indicated that, due to incorporation of reinforcing filler materials, onset temperature increases by about $4.5 \%$ while degradation temperature increased by $6 \%$ from virgin polypropylene. From these findings, it can be concluded that the composites have gained slightly better thermal stability than PP or in other words, the addition of sawdust increases the thermal stability of PP to some extent. Generally, PP has a comparatively low thermal stability due to its volatile nature and relatively low melting point. When the addition of sawdust was made they covered the PP grains and therefore tends to decrease its volatility resulting in improvement of its thermal stability. This result is in good agreement with previous studies (Syed et al., 2011; Mohanty et al., 2006).

\section{Conclusion}

The investigation reports the fabrication and the study of the physio-mechanical and thermal properties of fabric/ polypropylene and fabric-wood saw dust/polypropylene synergic composites. Overall tensile strength of the hybrid composites was lower than that of pure PP matrix. Tensile strength decreased with increasing wood particle contents up to a certain amount and then increased again. While increasing wood saw dust, elastic modulus of the hybrid composites also increased up to a certain amount and then decreased again. Similar trend was observed in case of flexural strength and modulus. However, from further studies of varying compositions an optimum degree of reinforcements in hybrid composites would be possible to determine with a combination of maximum strength and modulus. Hardness of the composites was observed to vary slightly from the pure PP. Water absorption of the hybrid composites significantly increased with increasing wood saw dust content. Maximum water absorption was found in $20 \%$ wood saw dust/fabric reinforced composite while, minimum in virgin PP. SEM micrographs of the hybrid composites revealed micro pores between the interface of the matrix and reinforcing materials. Moreover, the thermal stability of composites improved with incorporation of cotton fibers and wood saw dust particles.

\section{Acknowledgements}

The authors would like to thank Bangladesh University of Engineering and Technology (BUET) in funding the present research.

\section{References}

Adhikary KB, Pang S and Staiger MP (2008), Dimensional stability and mechanical behaviour of wood-plastic composites based on recycled and virgin high-density polyethylene (HDPE), Comp. Part B 39: 807-815. 
Alsina OL, De Carvalho LH, Ramos Filho FGD and d'Almeida JR (2005), Thermal properties of hybrid lignocellulosic fabric-reinforced polyester matrix composites, Poly. Test. 24: 81-85. DOI:org/10.1016/ j.polymertesting.2004.07.005

Aspiras FF and Manalo JRI (1995), Utilization of textile waste cuttings as building material, J. Mater. Process. Technol 48: 379-384.

Bao LR and Yee AF (2002), Effect of temperature on moisture absorption in a bismaleimide resin and its carbon fiber composites, Polymer 43: 3987-3997.

Bismarck A, Aranberri-Askargorta I, Springer J, Lampke T, Wielage B, Stamboulis A and Limbach HH (2002), Surface characterization of flax, hemp and cellulose fibers; surface properties and the water uptake behavior, Poly. Comp. 23: 872-894.

Biswas S, Kindo S and Patnaik A (2011), Effect of fiber length on mechanical behavior of coir fiber reinforced epoxy composites, Fibers Polym. 12: 73-78.

Eleiche AM and Amin GM (1986), The effect of unidirectional cotton fibre reinforcement on the friction and wear characteristics of polyester. Wear 112: 67-78. DOI:org/10.1016/0043-1648(86)90201-2

Esfandiari A (2008), The statistical investigation of mechanical properties of $\mathrm{PP} /$ natural fibers composites, Fibers Polym. 9: 48-54.

Fervel V, Mischler S and Landolt D (2003), Lubricating properties of cotton transfer films studied with a pin-on-disc apparatus, Wear 254: 492-500. DOI:org/ 10.1016/S0043-1648(03)00131-5

Garside P and Wyeth P (2003), Identification of cellulosic fibres by FTIR spectroscopy-thread and single fibre analysis by attenuated total reflectance, Stud. Conser. 48: 269-275. DOI:org/10.1179/sic.2003.48.4.269

Gibson, SL, Baranauskas V, Riffle JS and Sorathia U (2002), Cresol novolac-epoxy networks: properties and processability, Polymer 43: 7389-7398.

Hossain MF, Islam MK and Islam MA (2014), Effect of chemical treatment on the mechanical and physical properties of wood saw dust particles reinforced polymer matrix composites, Procedia Engg. 90: 39-45.
Ichazo MN, Albano C, Gonzalez J, Perera R and Candal MV (2001), Polypropylene/wood flour composites: treatments and properties, Comp. struct. 54: 207-214.

Idrus MM, Hamdan S, Rahman MR and Islam MS (2011), Treated tropical wood sawdust-polypropylene polymer composite: Mechanical and morphological study, $J$. biomat. and nanobiotech. 2: 435.

Islam MK and Sharif A (2016), Nanocharacterization of interface between natural fiber and polymer matrix: an overview, Comp. Interf. 23: 105-123.

Jawaid M, Khalil HA and Bakar AA (2011a), Woven hybrid composites: Tensile and flexural properties of oil palm-woven jute fibres based epoxy composites. Materials Science and Engineering: A 528: 5190-5195. DOI:org/10.1016/j.msea.2011.03.047

Jawaid M, Khalil HA, Bakar A A and Khanam PN (2011b), Chemical resistance, void content and tensile properties of oil palm/jute fibre reinforced polymer hybrid composites, Mat. \& Des. 32: 1014-1019.

Khalil HA, Issam AM, Shakri MA, Suriani R and Awang AY (2007), Conventional agro-composites from chemically modified fibres, Ind. Crops and Prod. 26: 315-323. DOI:org/10.1016/j.indcrop.2007.03.010

Khan MN, Roy JK, Akter N, Zaman HU, Islam T and Khan RA (2012), Production and properties of short jute and short e-glass fiber reinforced polypropylene-based composites. Open J of comp. mat. 2: 40.

Lee BH, Kim HJ and Yu WR (2009), Fabrication of long and discontinuous natural fiber reinforced polypropylene biocomposites and their mechanical properties, Fibers Polym 10: 83-90.

Lei Y, Wu Q, Yao F and Xu Y (2007), Preparation and properties of recycled HDPE/natural fiber composites. Comp. Part A: App. Sci. and Man. 38: 1664-1674. DOI:org/10.1016/j.compositesa.2007.02.001

Liu GR (1997), A step-by-step method of rule-of-mixture of fiber-and particle-reinforced composite materials. Compos. Struct. 40: 313-322. doi.org/10.1016/S02638223(98)00033-6

Liu XY and Dai GC (2007), Surface modification and micromechanical properties of jute fiber mat reinforced polypropylene composites, eXPRESS Poly. Lett. 1: 299-307 
Mohanty S, Verma SK and Nayak SK (2006), Dynamic mechanical and thermal properties of MAPE treated jute/HDPE composites. Comp. Sci. and Tech. 66: 538-547. DOI:org/10.1016/j.compscitech.2005.06.014

Nam S and Netravali AN (2006), Green composites. I. Physical properties of ramie fibers for environment-friendly green composites, Fibers Polym 7: 372-379.

Parthasarthy G, Sevegney M and Kannan RM (2002), Rheooptical Fourier transform infrared spectroscopy of the deformation behavior in quenched and slow-cooled isotactic polypropylene films. $J$ of Poly. Sci. Part B: Poly. Phy. 40: 2539-2551.

Pérez E, Famá L, Pardo SG, Abad MJ and Bernal C (2012), Tensile and fracture behaviour of $\mathrm{PP} /$ wood flour composites. Comp. Part B: Eng. 43: 2795-2800. DOI:org/10.1016/j.compositesb.2012.04.041

Saheb DN and Jog JP (1999), Natural fiber polymer composites: a review, Adv. in poly. Tech. 18: 351-363.

Sastra HY, Siregar P, Sapuan SM, Leman Z and Hamdan MM (2005), Flexural properties of Arenga pinnata fibre reinforced epoxy composites, American J Appl. Sci. 21-24.

Seki Y, Sarikanat M and Sever K (2010), Effect of the low and radio frequency oxygen plasma treatment of jute fiber on mechanical properties of jute fiber/polyester composite, Fibers Polym. 11: 1159-1164.

Shubhra QT, Alam AKMM and Gafur MA (2010), Characterization of plant and animal based natural fibers reinforced polypropylene composites and their comparative study, Fibers Polym. 11: 725-731.

Snijder MH and Bos HL (2000) Reinforcement of polypropylene by annual plant fibers: optimisation of the coupling agent efficiency, Comp. Interf. 7: 69-75.
Stark NM and Rowlands RE (2003), Effects of wood fiber characteristics on mechanical properties of wood/polypropylene composites, Wood Fiber Sci. 35: 167-174.

Syed MA, Akhtar S and Syed AA (2011), Studies on the physico-mechanical, thermal and morphological behaviors of high density polyethylene/coleus spent green composites, J of App. Poly. Sci. 119: 1889-1895. DOI:org/10.1002/app.32905

Tanvir SI and Mahmood MT (2014), Solid Waste for Knit Fabric: Quantification and Ratio Analysis, J. Env. Earth Sci. 4: 68-80.

Thwe MM and Liao K (2002), Effects of environmental aging on the mechanical properties of bamboo-glass fiber reinforced polymer matrix hybrid composites, Composites Part A: App. Sci. and Manu. 33: 43-52. DOI:org/10.1016/S1359-835X(01)00071-9

Tserki V, Matzinos P and Panayiotou C (2003), Effect of compatibilization on the performance of biodegradable composites using cotton fiber waste as filler, J. Appl. Polym. Sci. 88: 1825-1835. DOI:org/10.1016/ S1359-835X(01)00071-9

Wang Y (2010), Fiber and textile waste utilization, Waste Biomass Valorization 1: 135-143.

Yang, HS, Kim HJ, Son J, Park HJ, Lee BJ and Hwang TS (2004), Rice-husk flour filled polypropylene composites; mechanical and morphological study, Comp. Struc. 63: 305-312. DOI:org/10. 1016/S0263-8223(03)00179-X

Zainudin ES, Yan LH, Haniffah WH, Jawaid $M$ and Alothman OY (2014), Effect of coir fiber loading on mechanical and morphological properties of oil palm fibers reinforced polypropylene composites, Poly. Comp. 35: 1418-1425. DOI:org/10.1002/pc.22794 